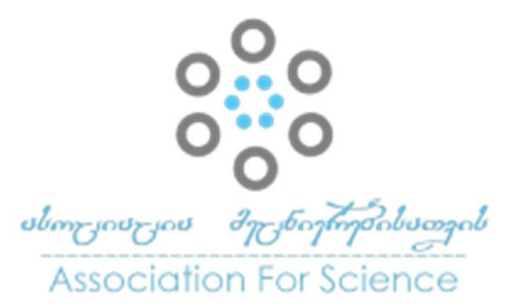

Georgian Scientists

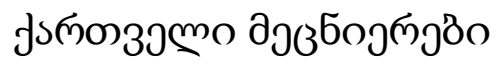

Vol. 3 I ssue 3, 2021

https://doi.org/10.52340/gs.2021.08.02

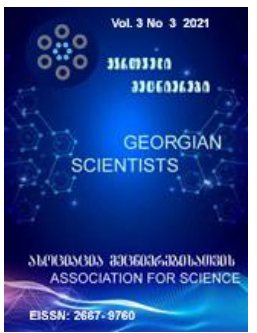

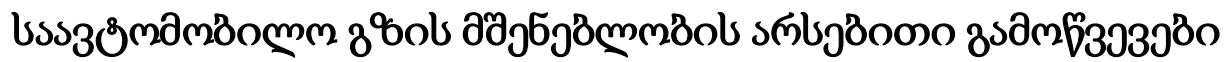

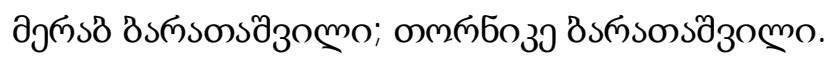

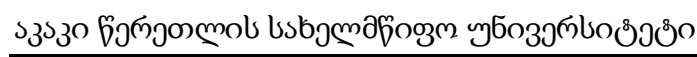

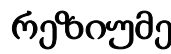

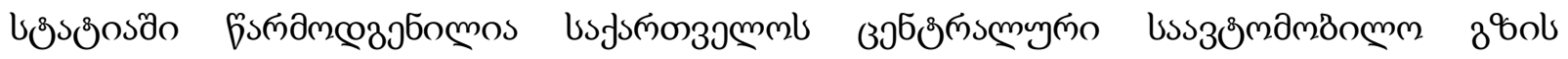

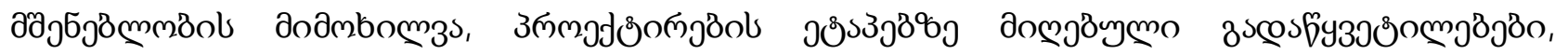

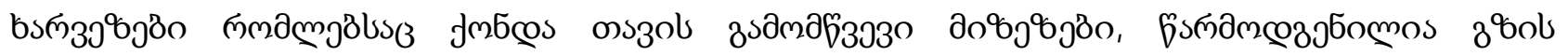

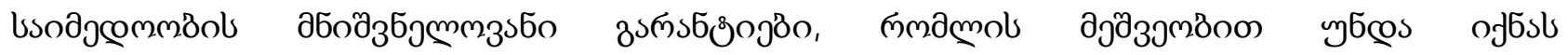

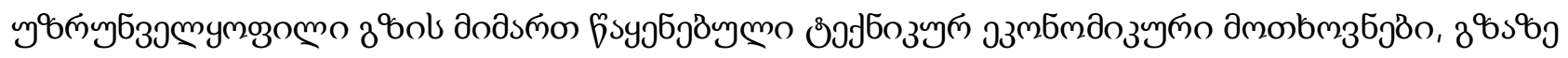

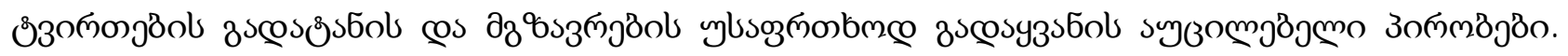

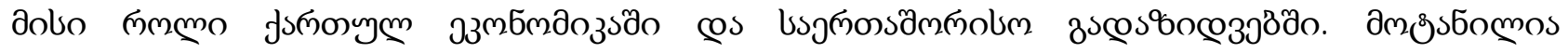

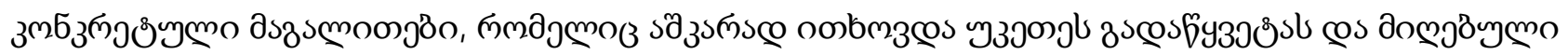

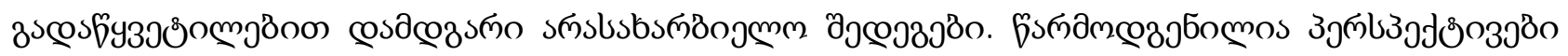

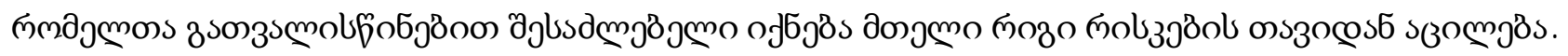

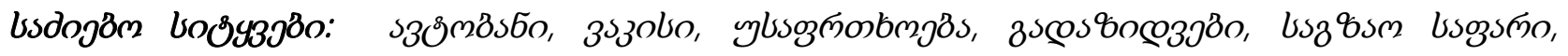

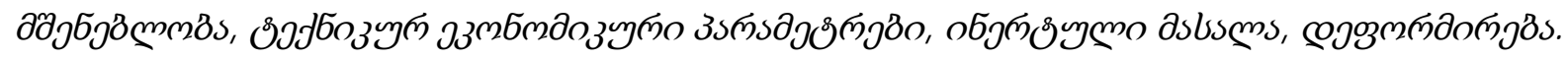




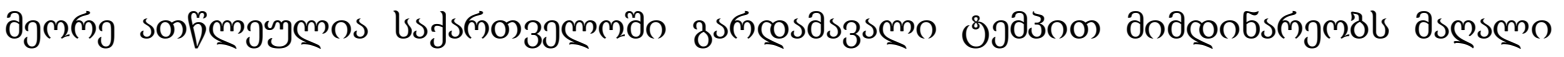

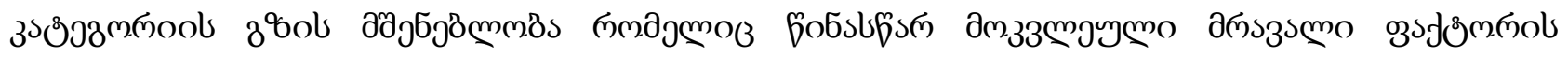

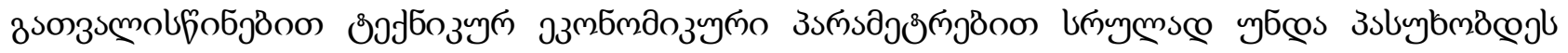

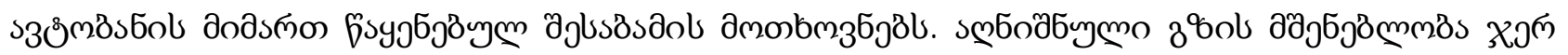

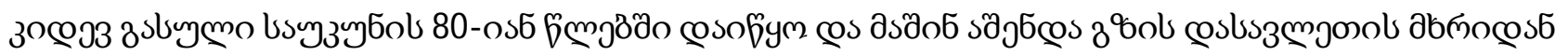

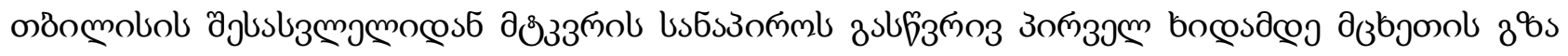

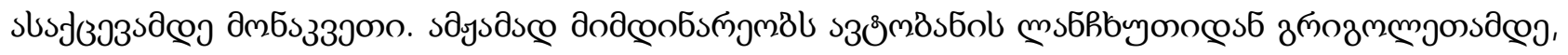

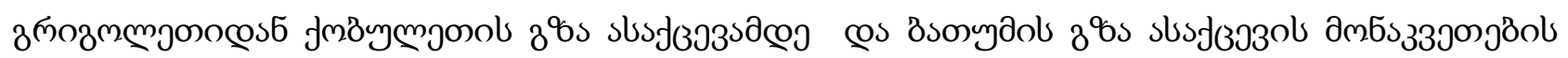

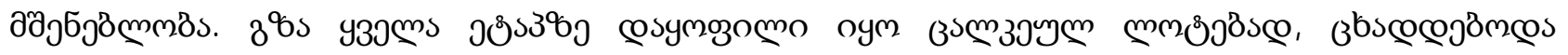

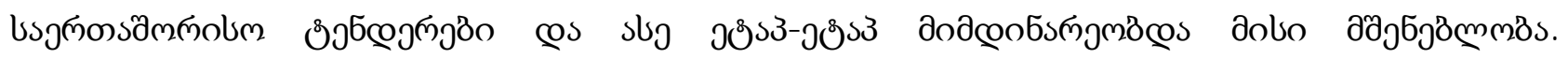

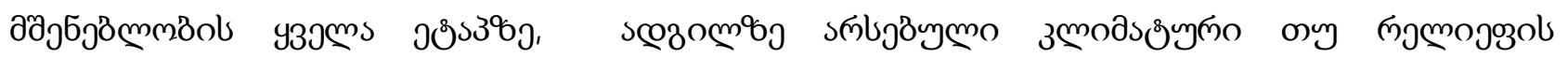

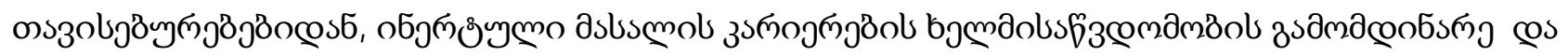

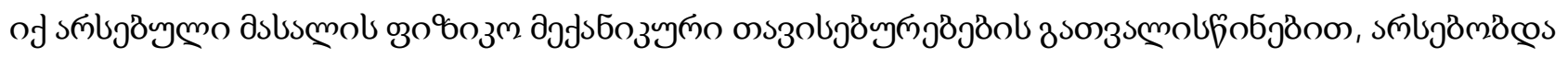

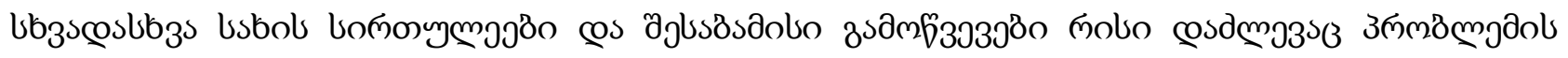

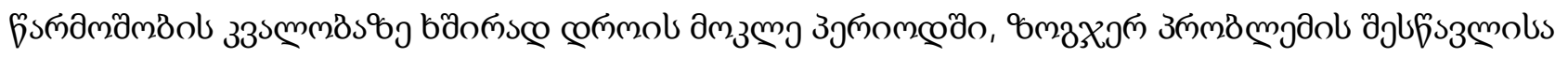

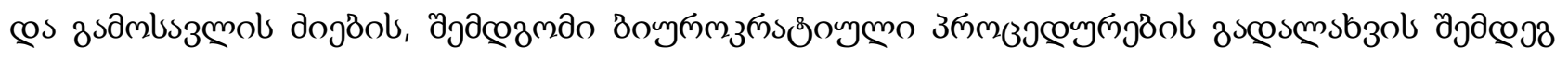

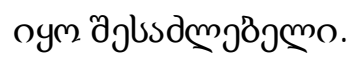

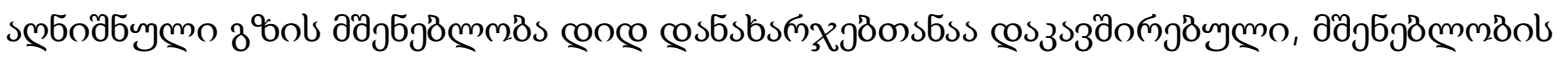

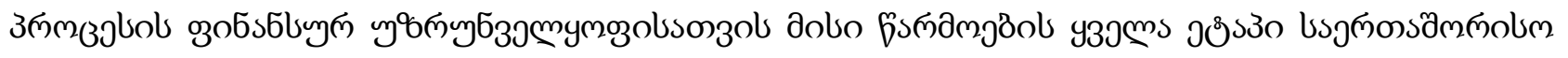

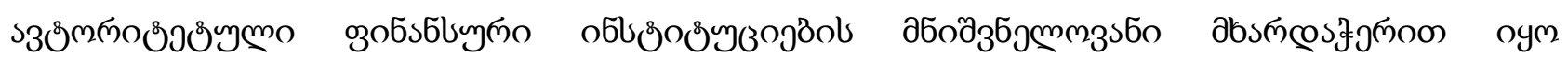

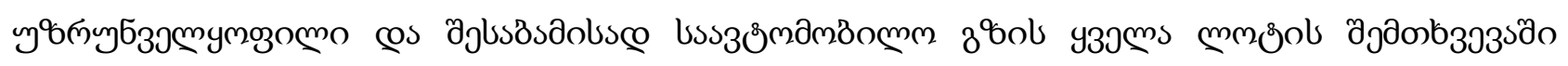

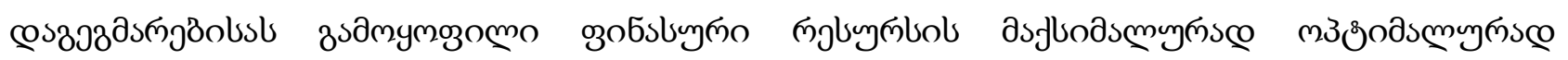

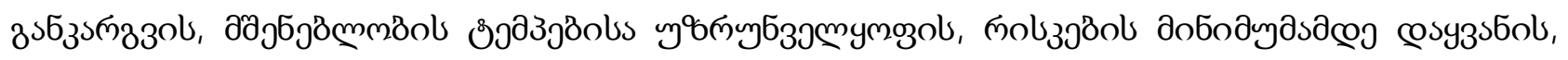

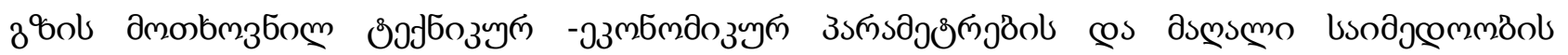

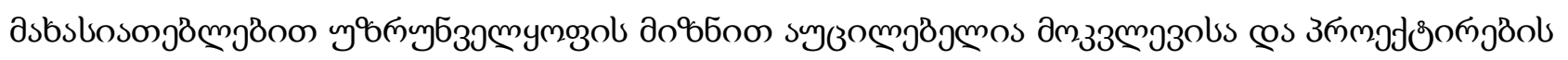

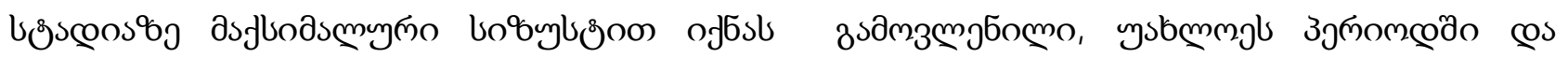

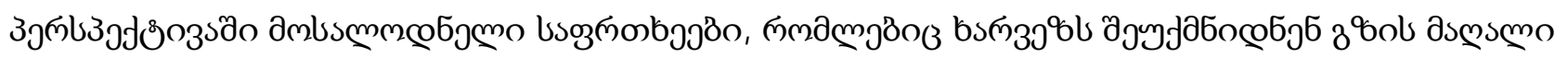

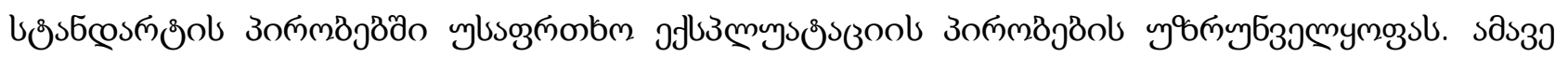

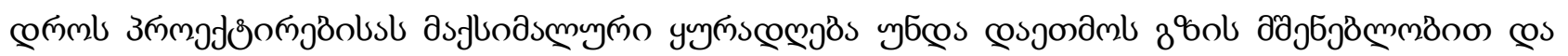

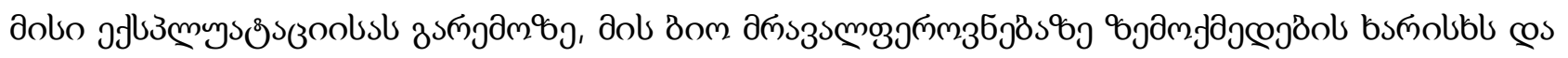

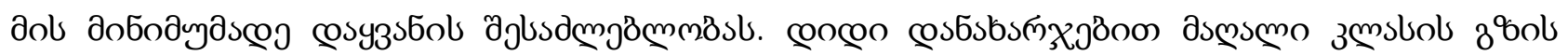

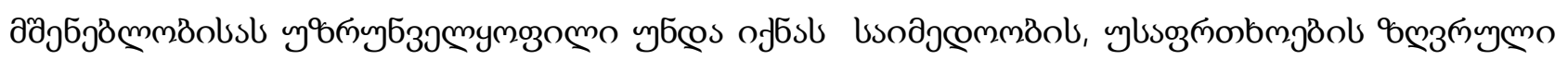

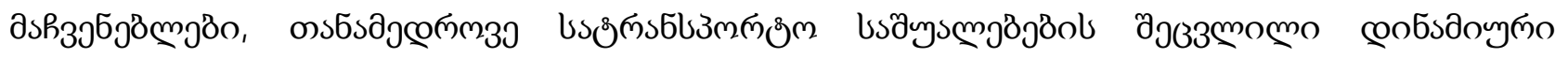

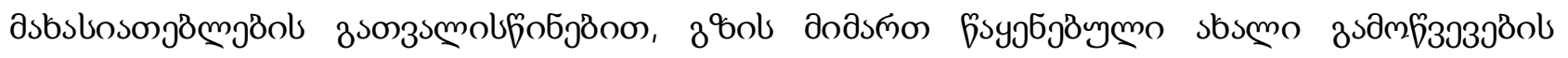

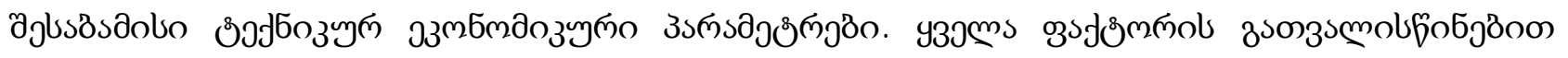

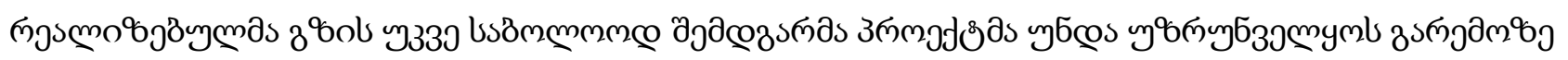

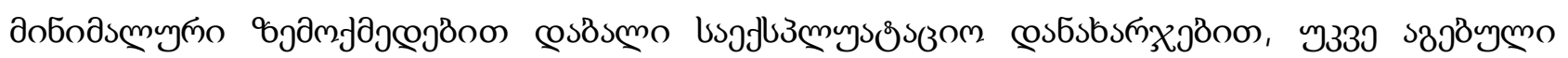

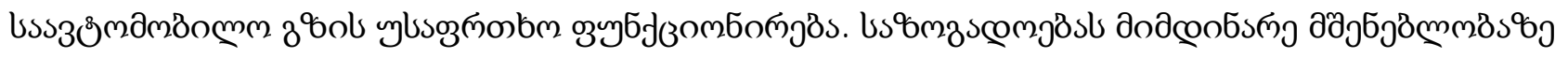

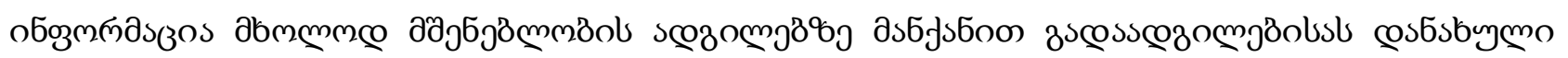




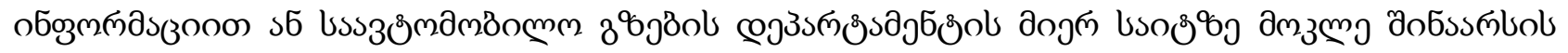

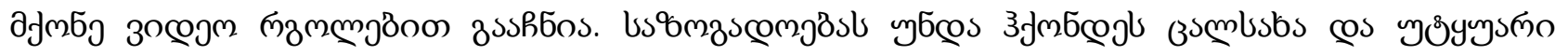

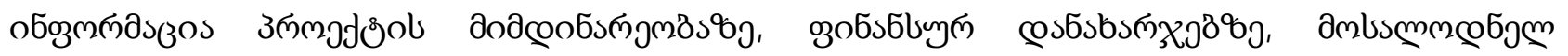

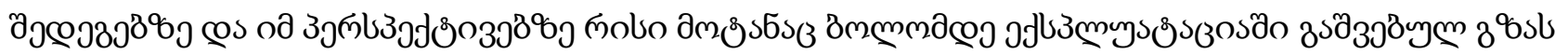

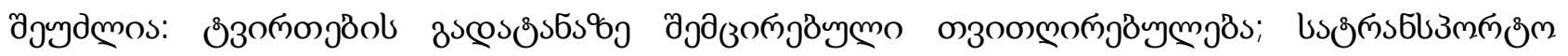

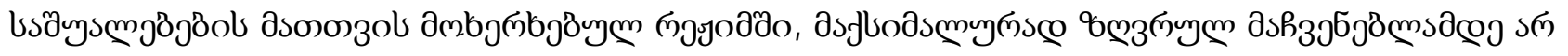

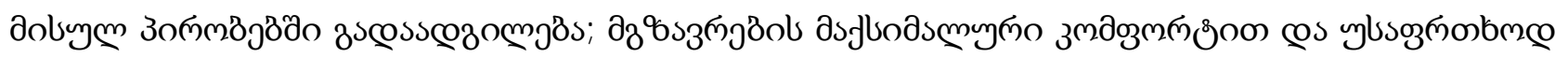

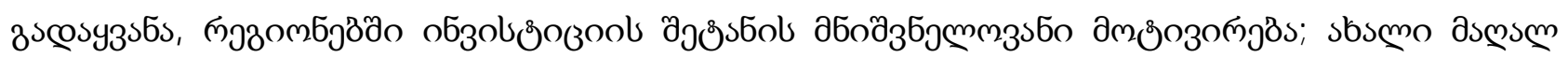

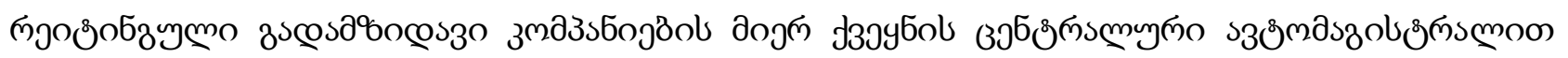

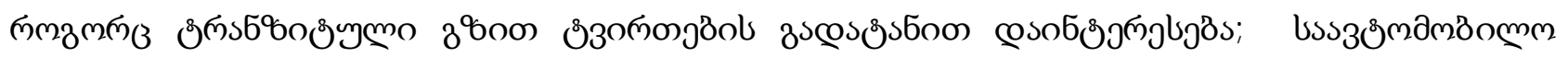

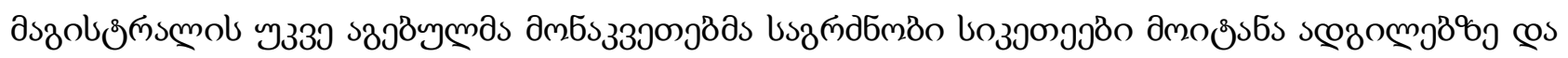

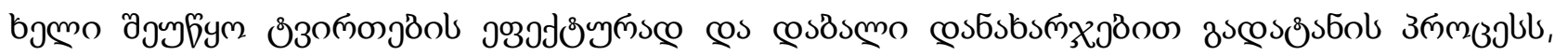

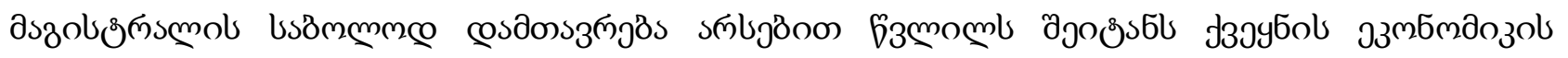

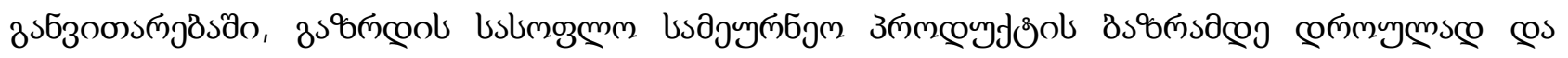

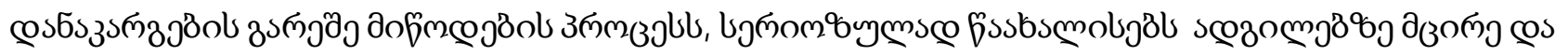

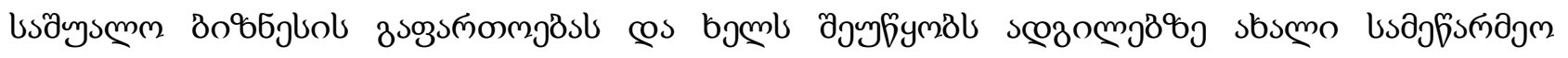

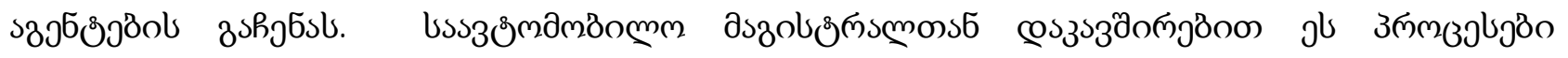

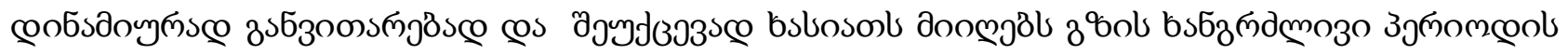

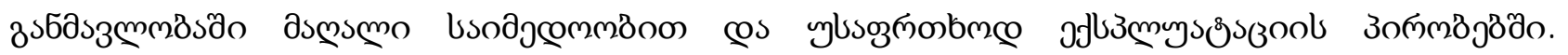

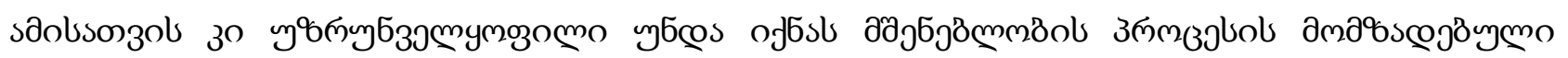

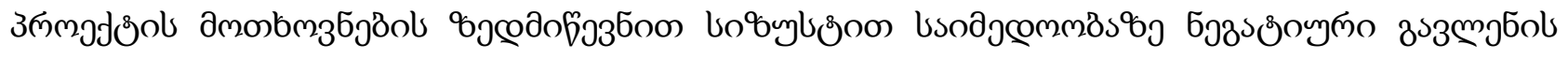

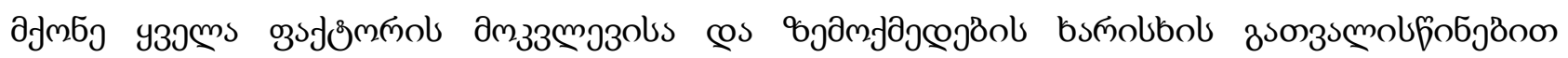

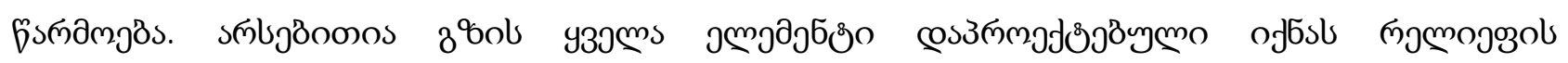

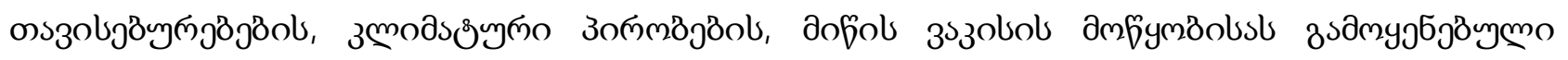

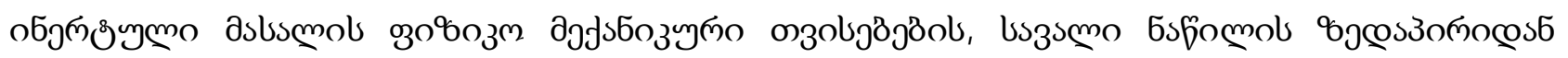

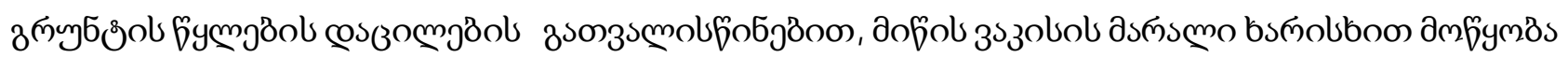

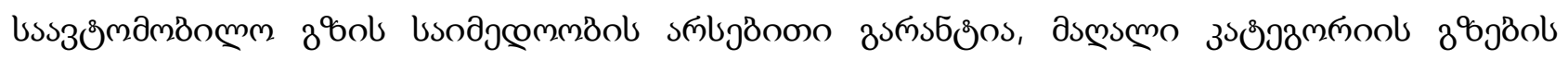

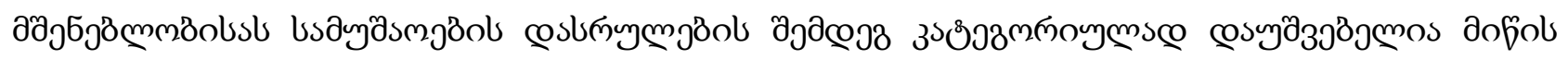

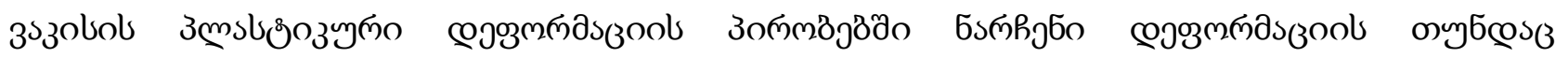

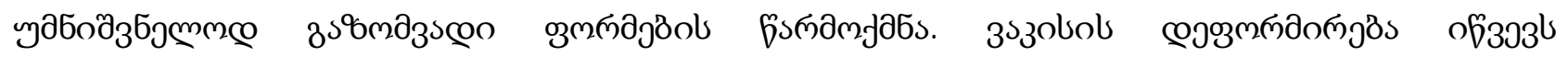

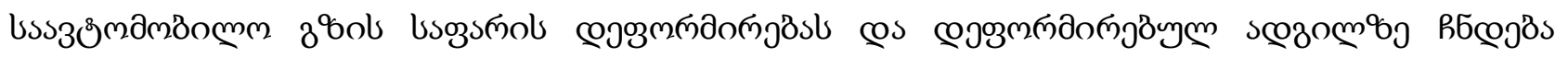

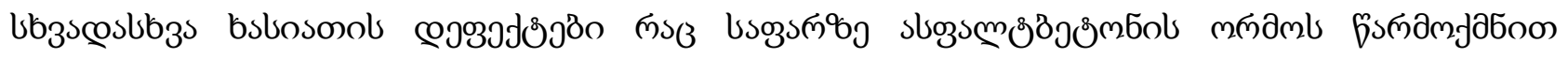

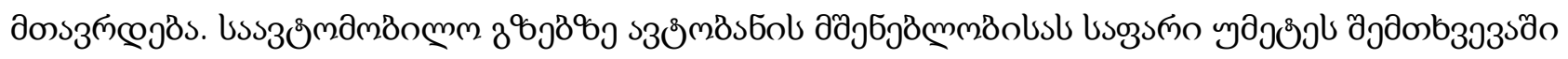

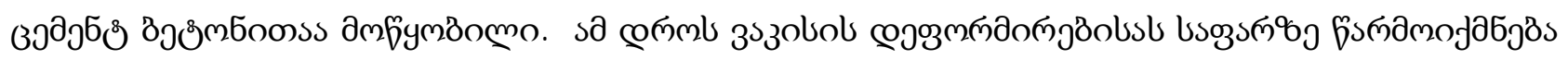

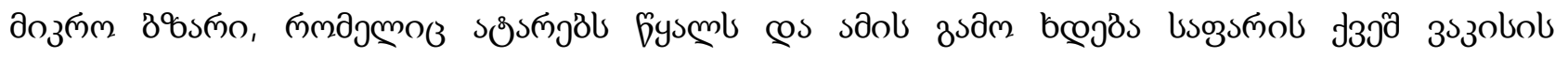

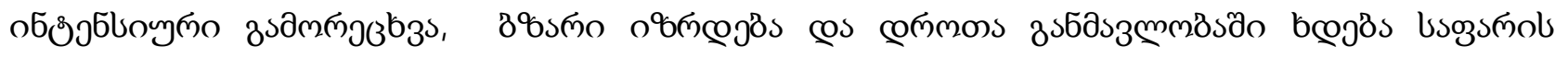

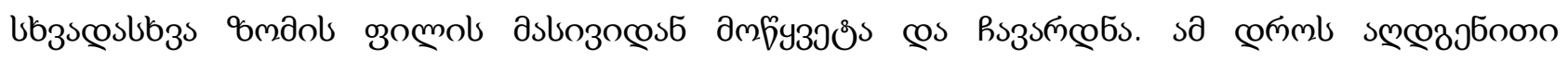

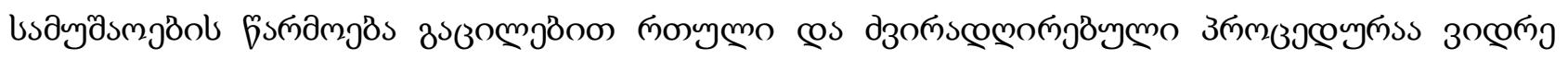

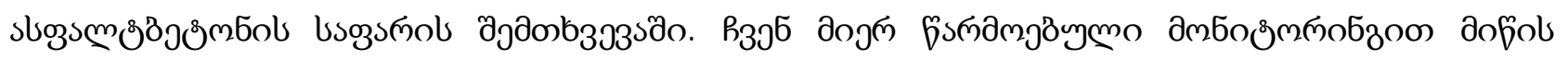

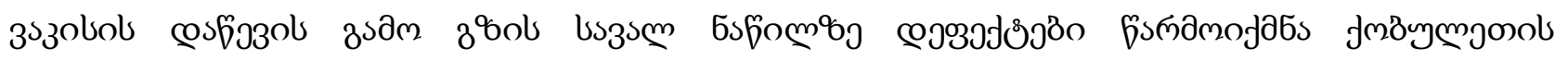




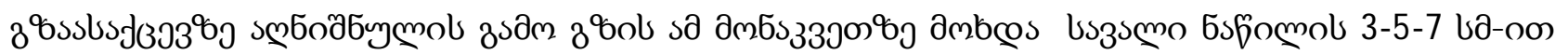

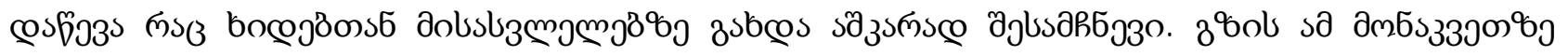

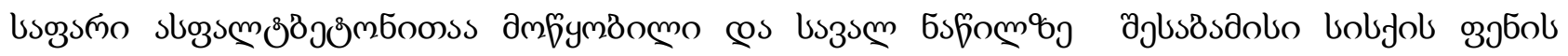

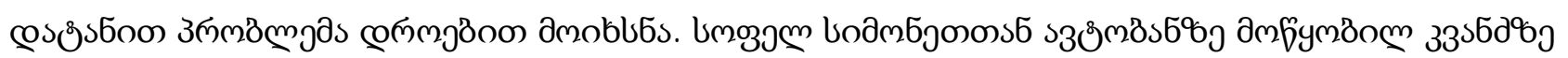

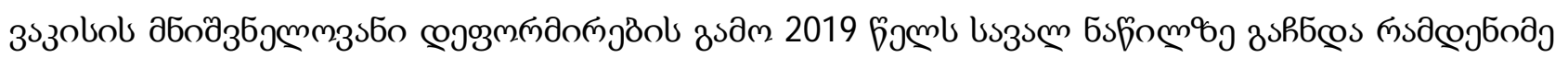

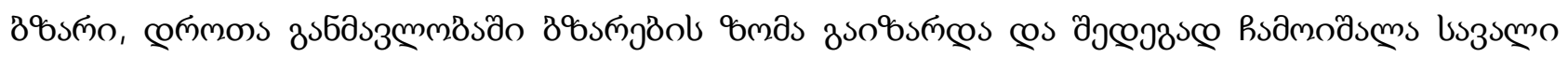

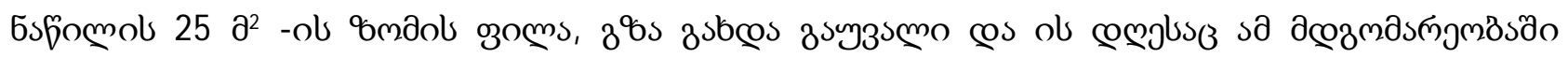

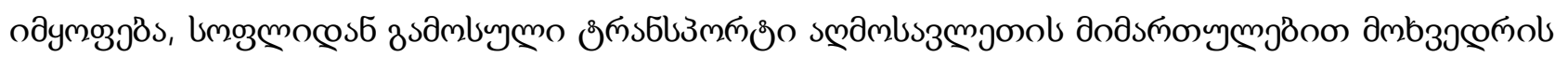

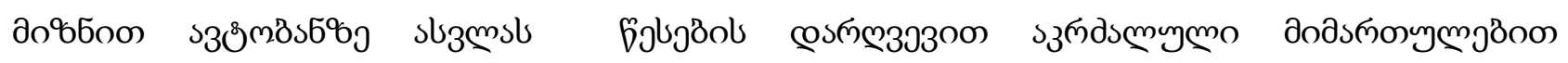

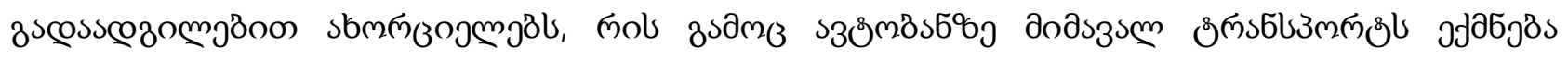

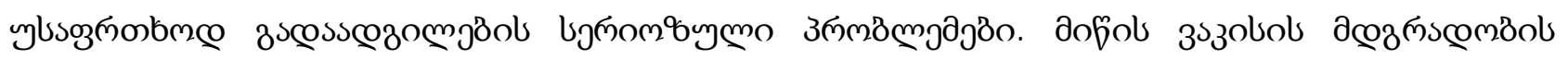

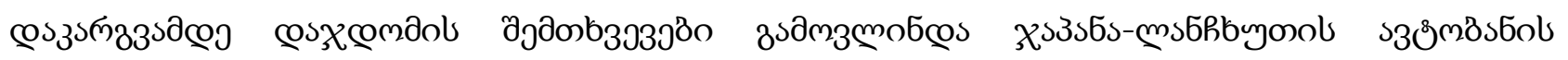

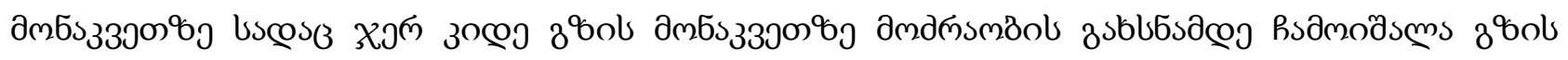

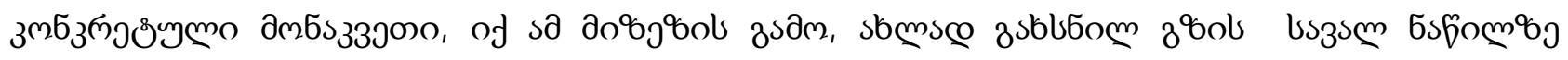

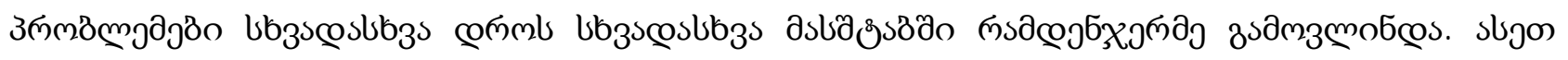

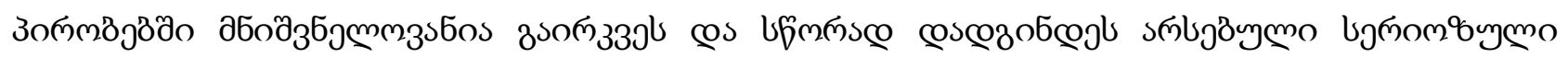

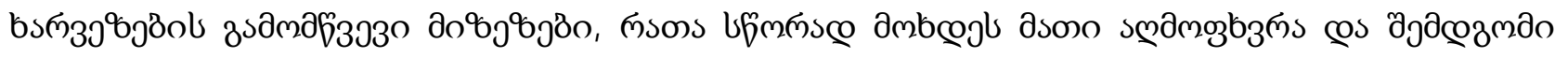

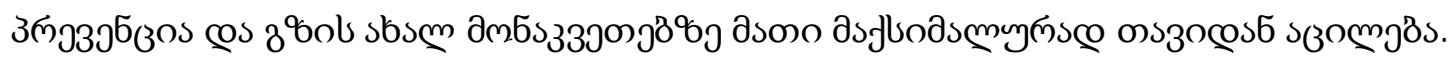

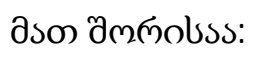

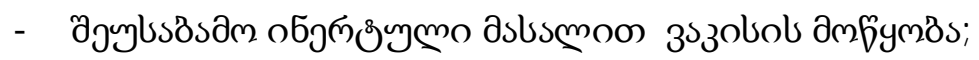

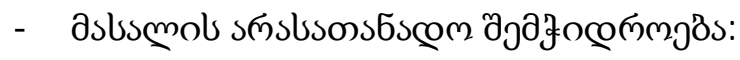

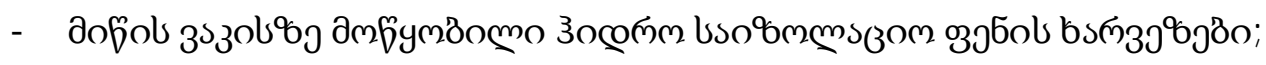

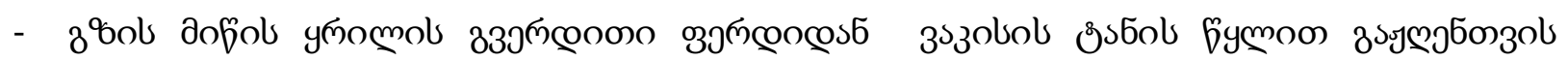

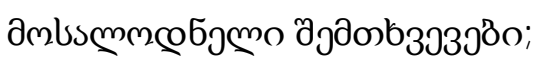

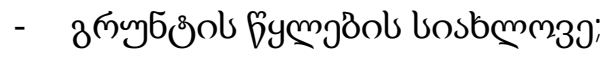

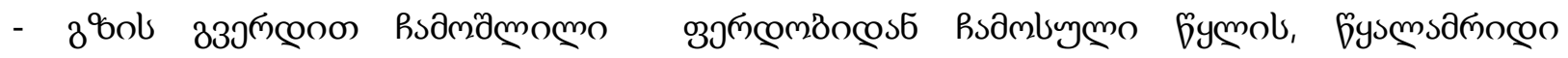

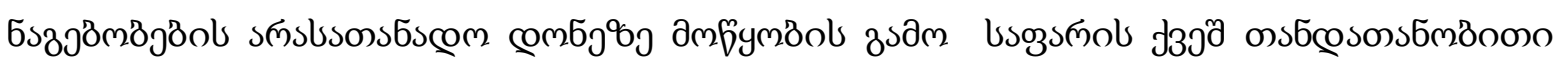

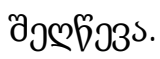

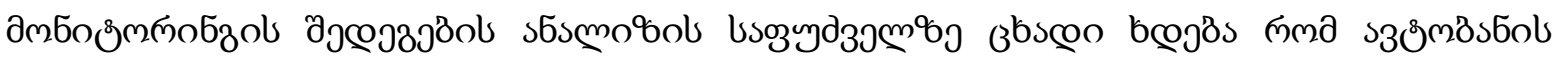

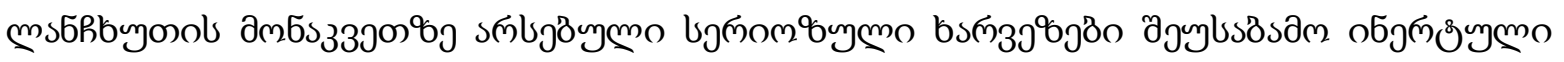

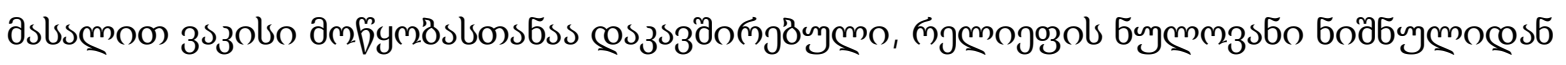

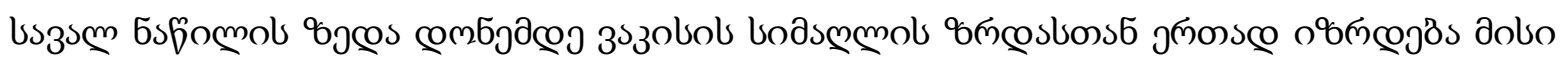

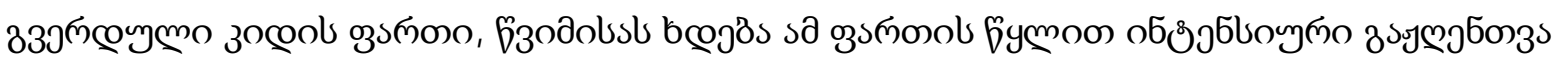

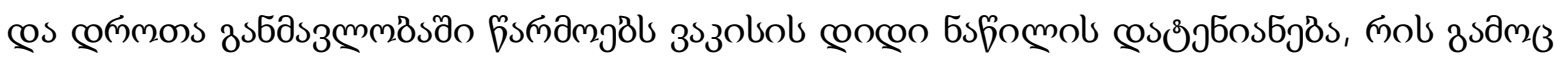

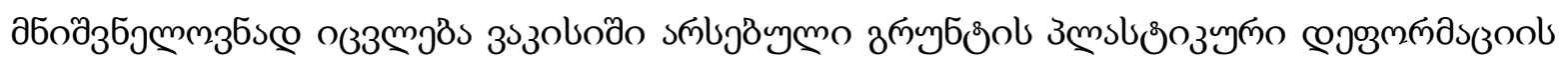

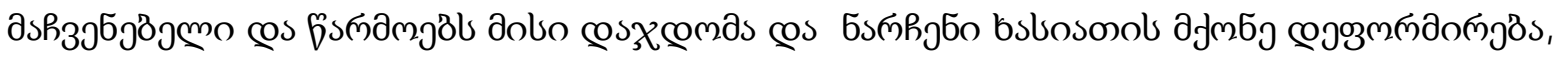

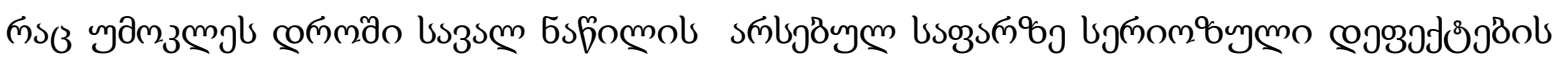

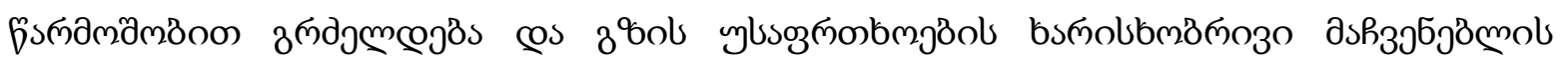

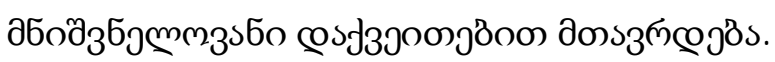




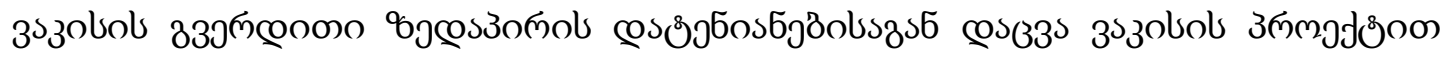

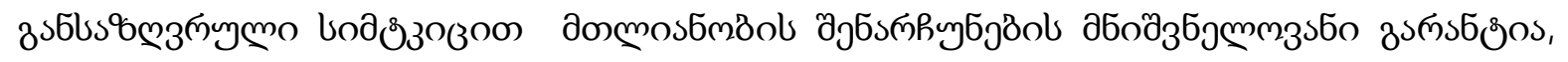

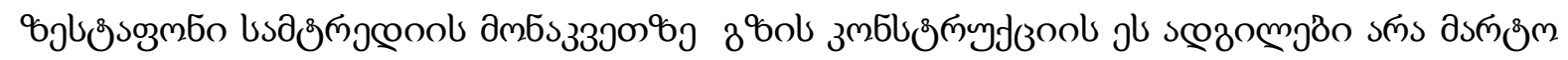

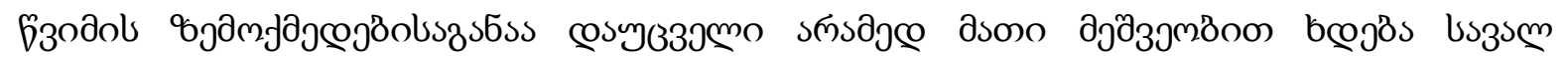

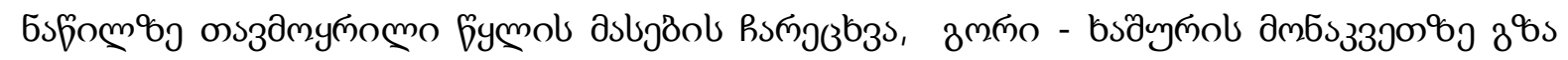

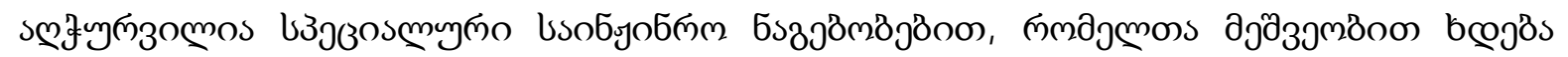

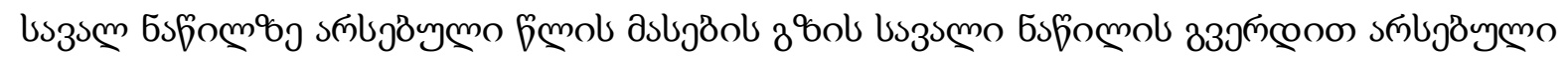

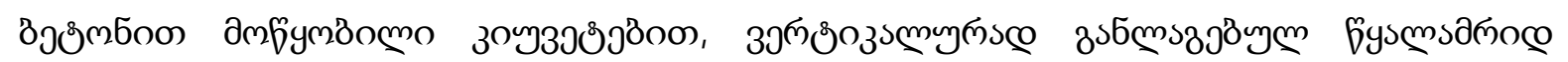

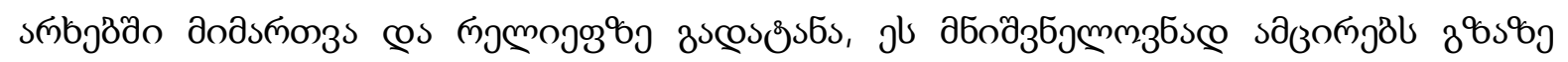

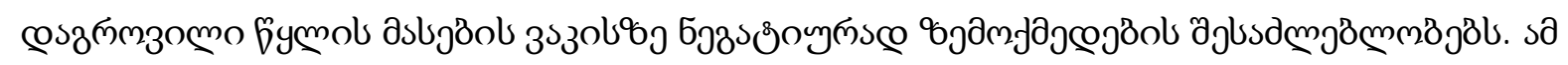

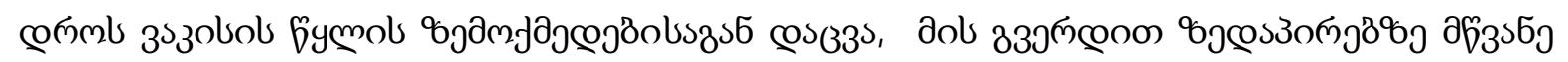

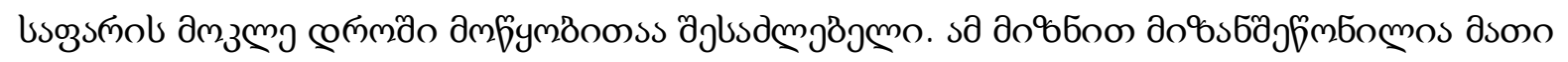

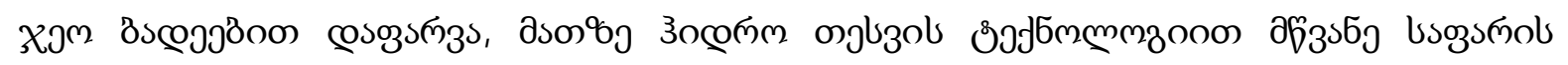

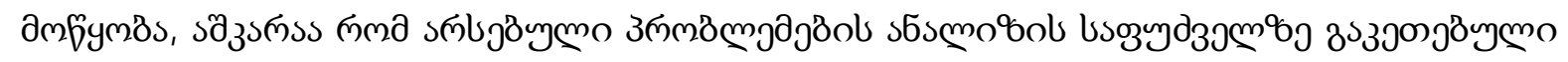

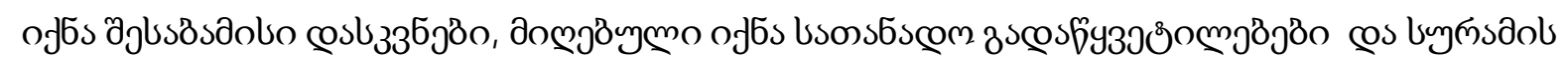

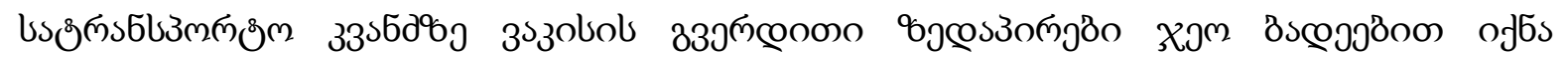

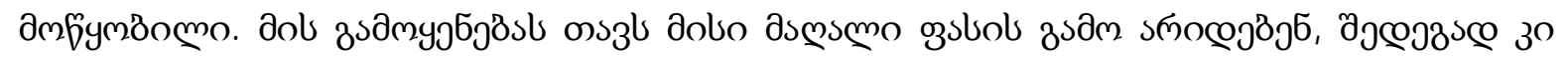

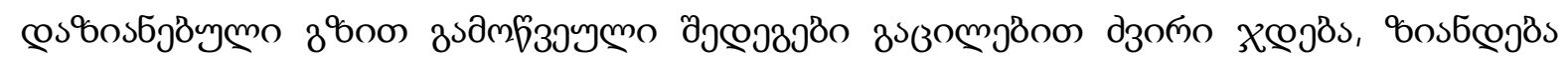

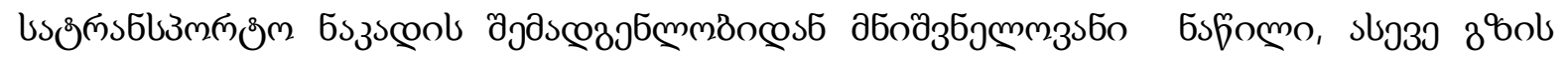

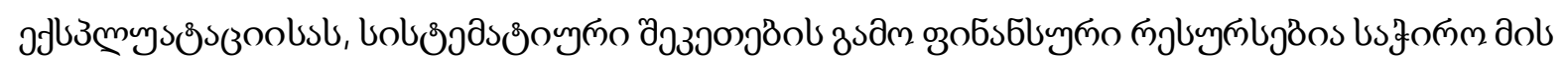

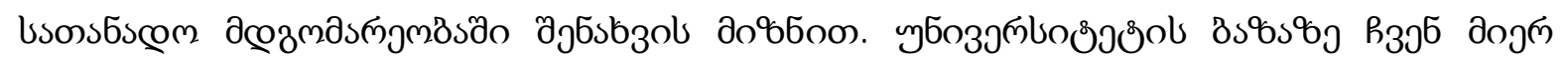

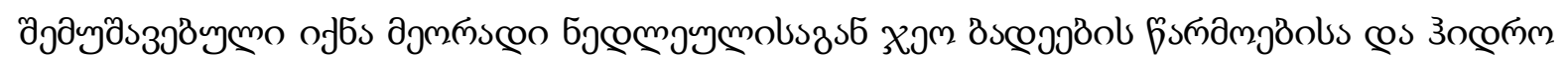

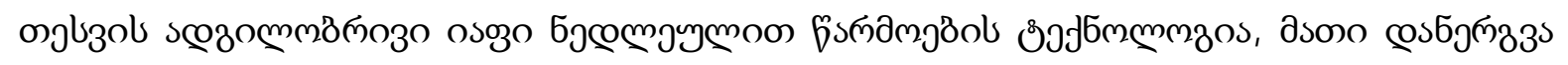

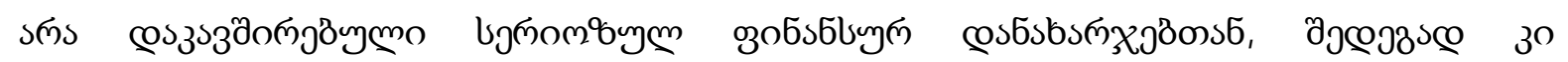

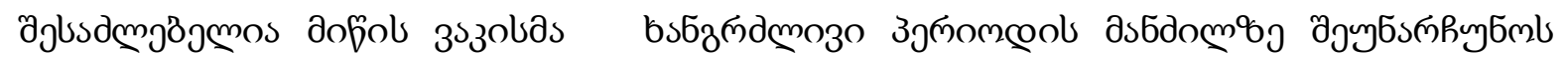

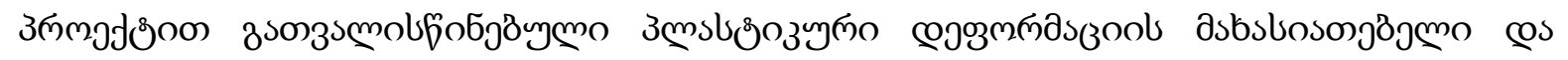

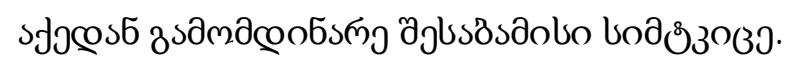

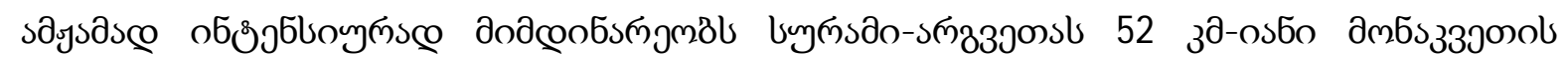

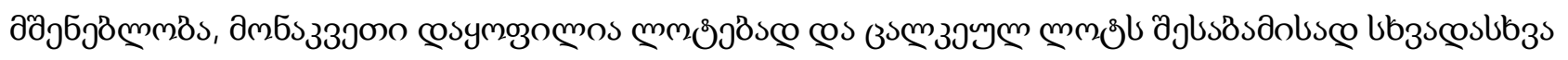

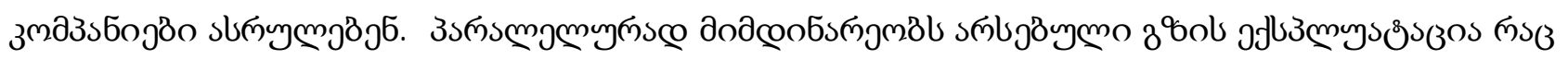

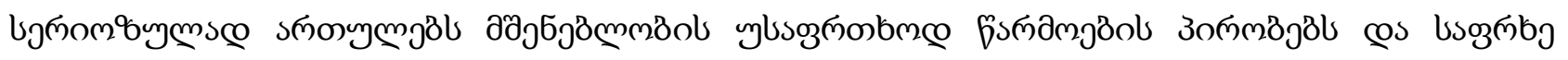

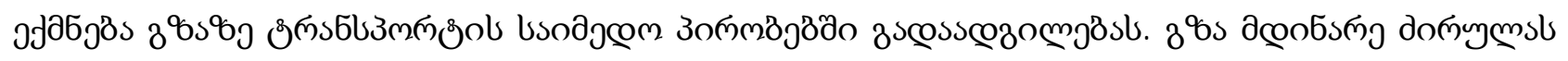

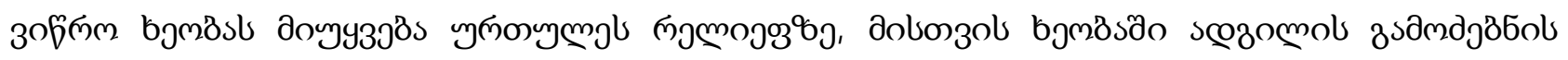

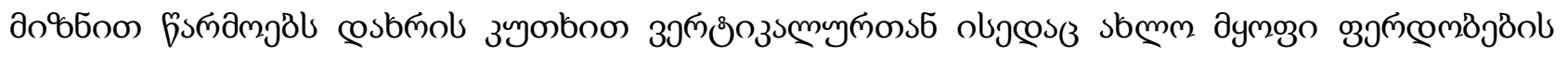

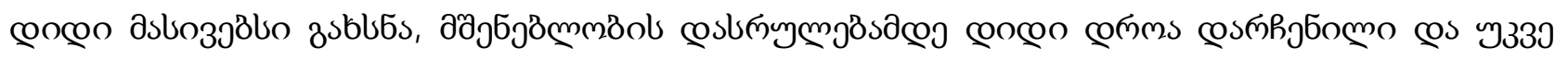

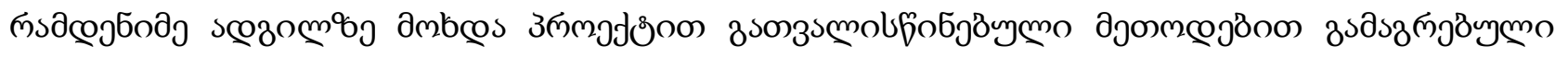

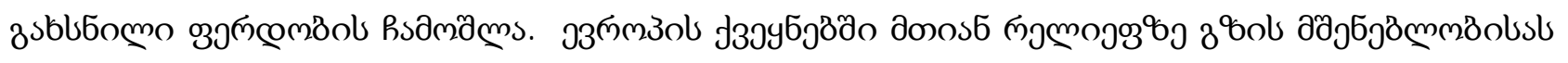

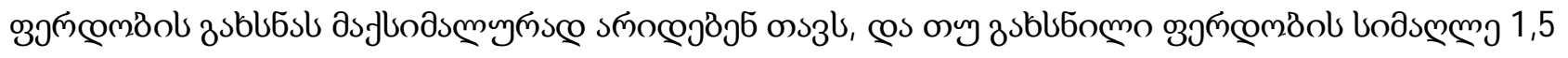

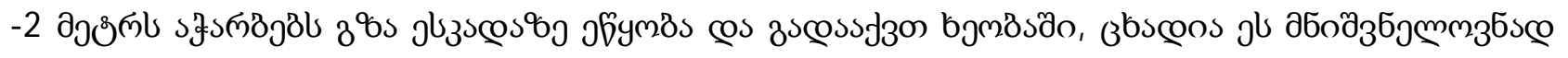

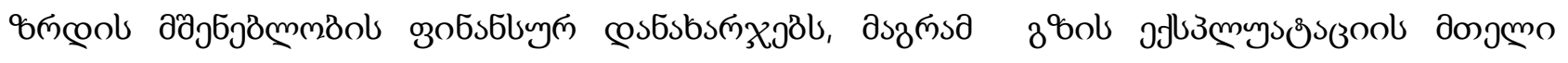




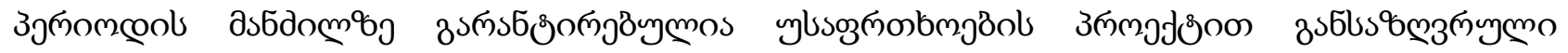
аsһзэб

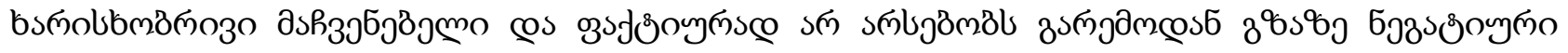

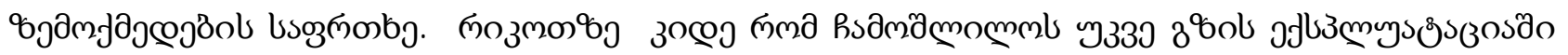

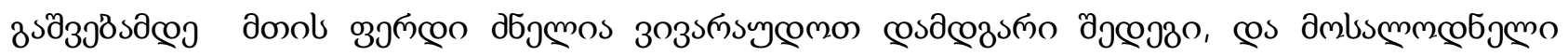

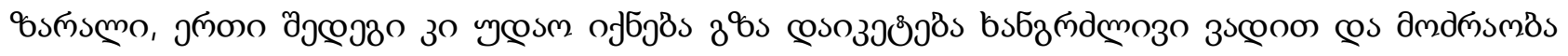

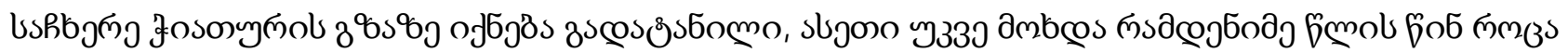

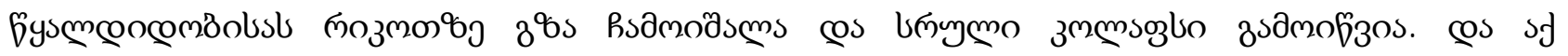

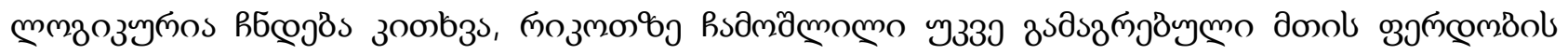

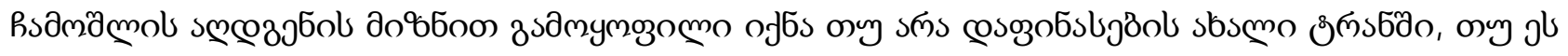

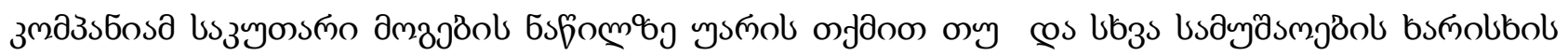

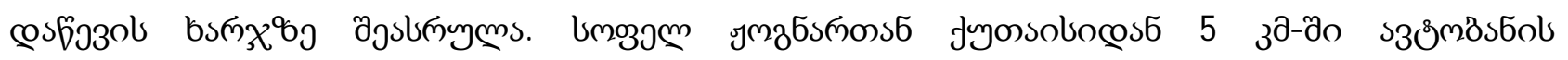

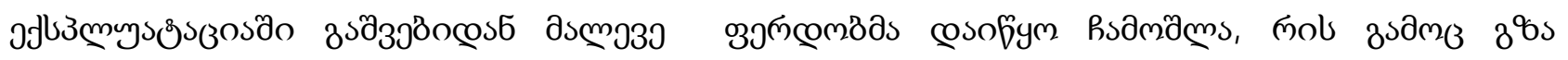

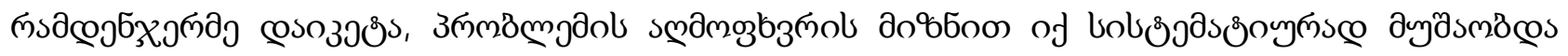

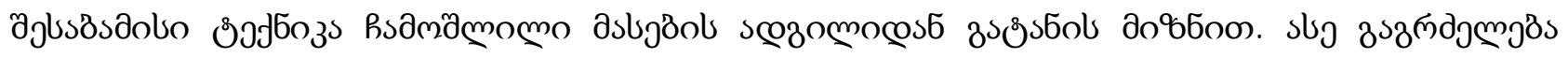

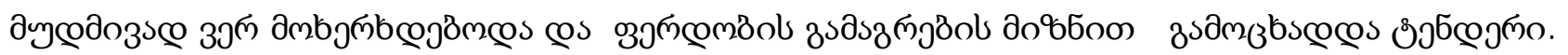

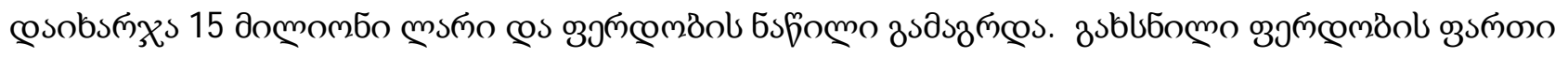

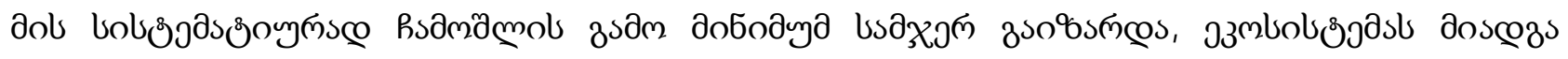

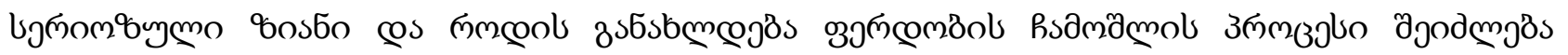

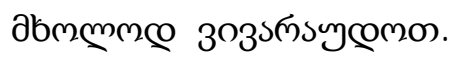

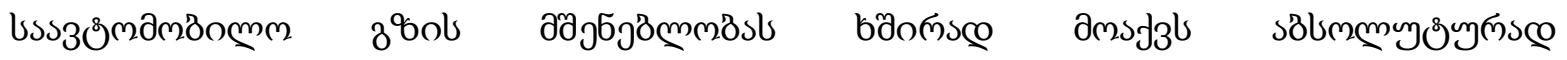

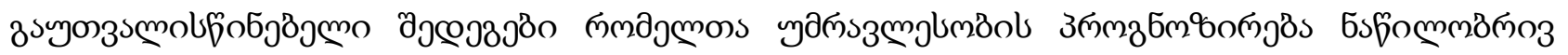

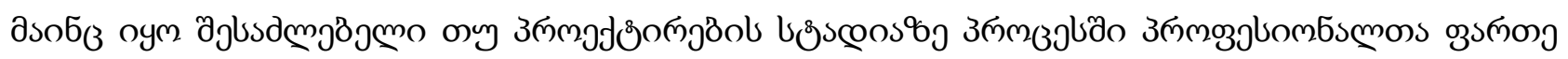

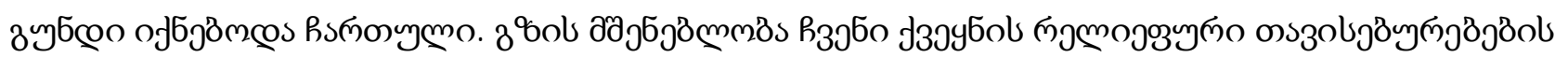

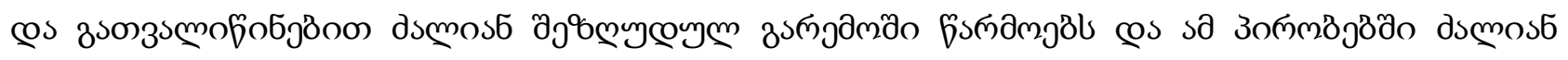

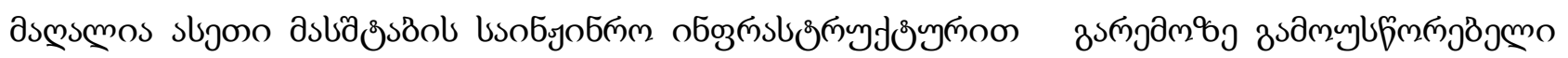

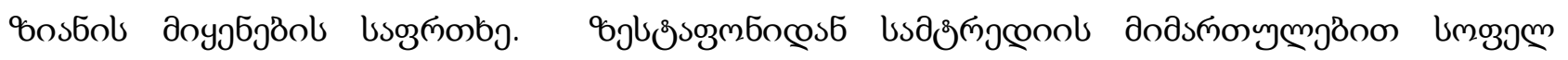

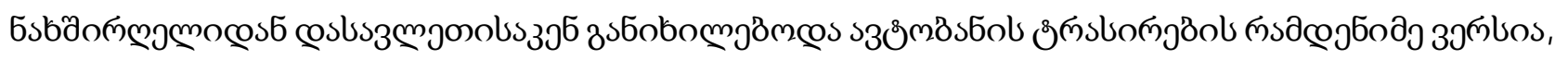

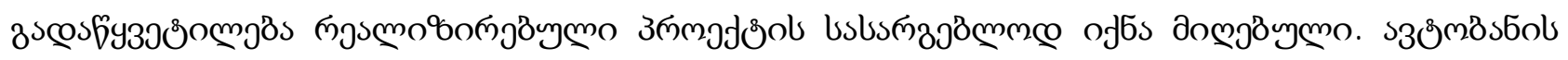

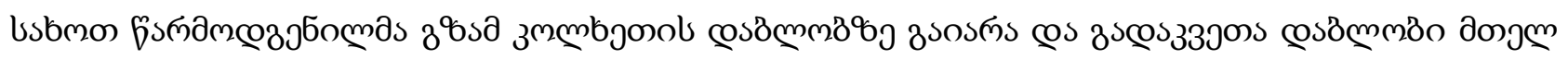

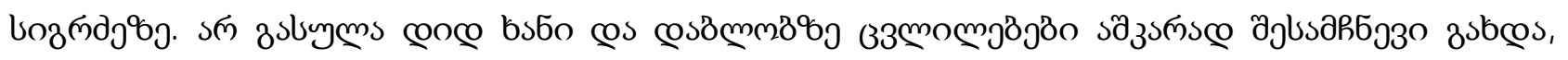

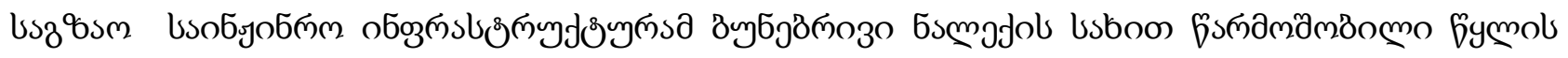

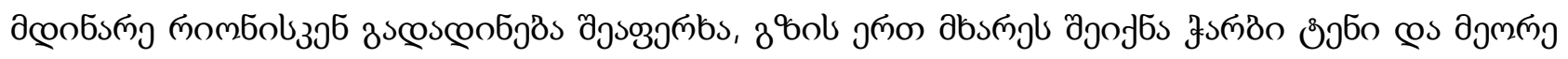

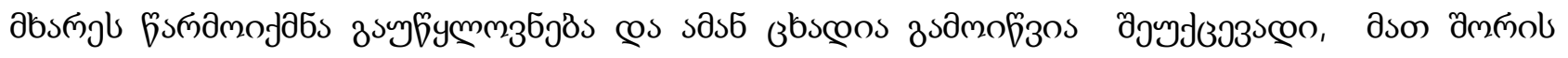

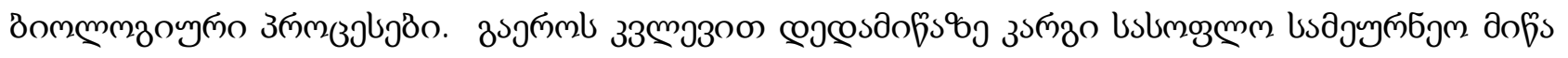

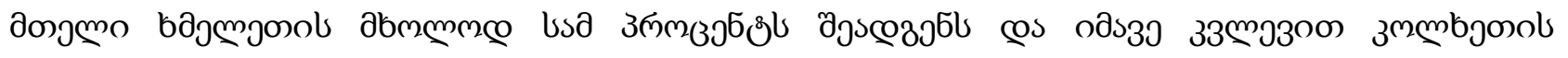

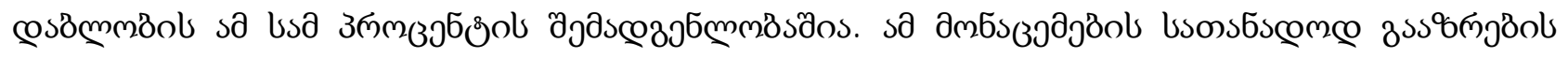

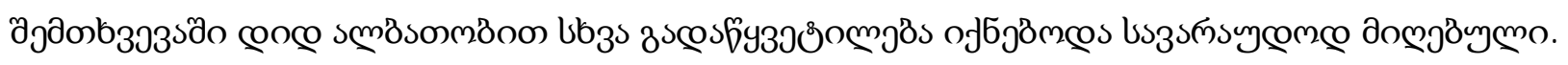




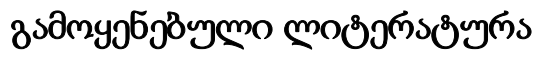

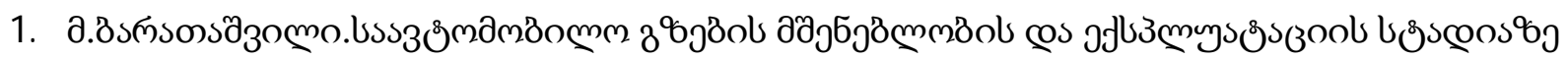

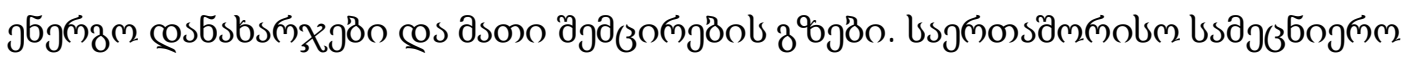

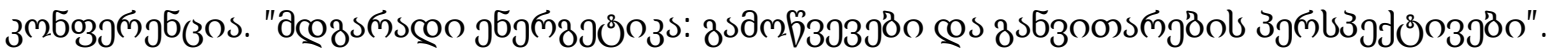

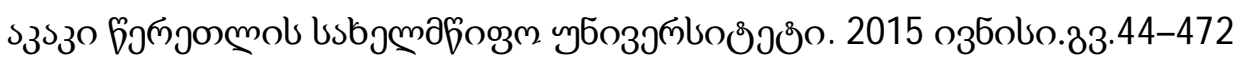

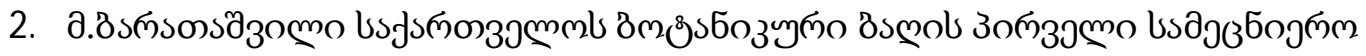

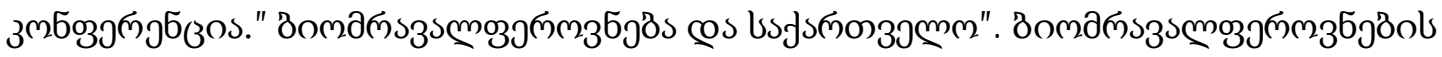

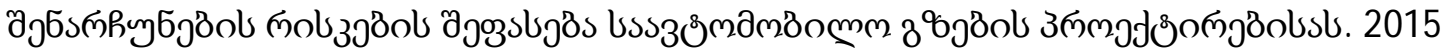
asobo. $33.21-24$.

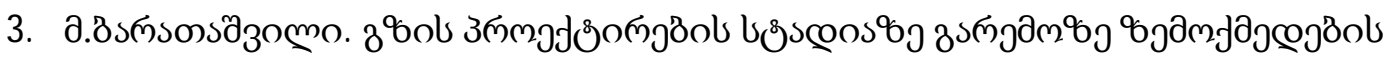

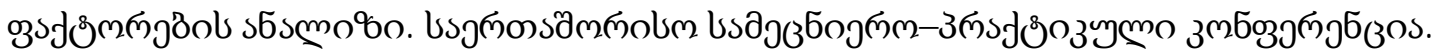

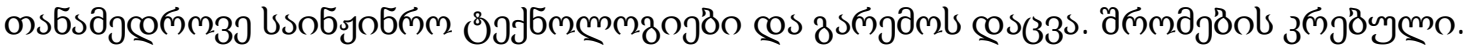

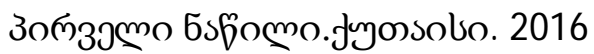

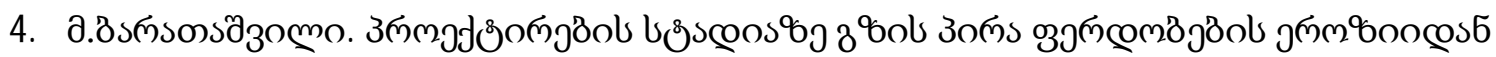

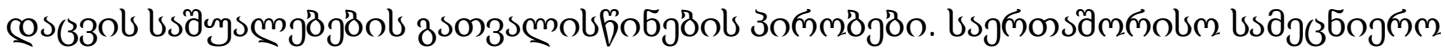

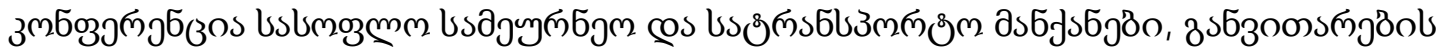

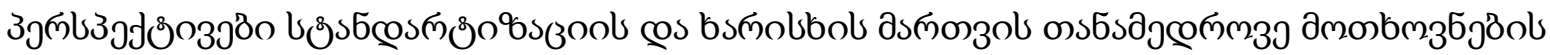

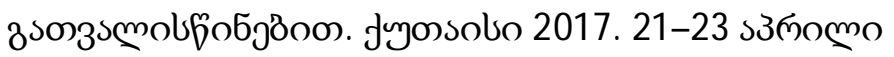

\section{Substantial challenges of road construction}

M erab Baratashvili; Tornike Baratashvili

\section{Resume}

In the form of a representative review of the construction of Central Drugs Georgia, solutions, acceptance of stages of design, deficiencies, names of their own reasons, important guarantees of trusts, which must be technically and painfully necessary transportation of goods and passengers. His role in the economy of Georgia and the international court. Concrete examples are taken, which, obviously, required good solutions and unfavorable results, half-baked in the result of your most important solution. Presented perspectives that follow are considered. W hat is permissible to avoid of risk.

\section{Keywords:}

Highway, slope, safety, transportation, road surface, construction, technical and economic parameters, inert material, deformation 